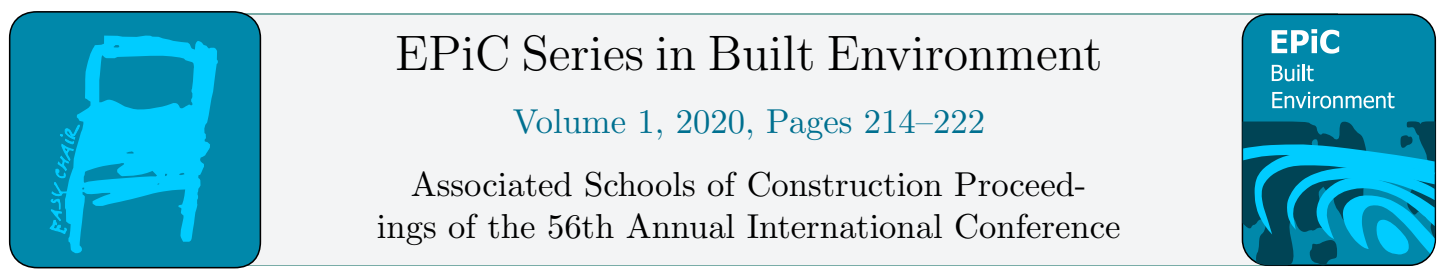

\title{
Evaluating the Use of Unmanned Aerial Systems (UAS) to Perform Low-Slope Roof Inspections
}

\author{
Dhaval Gajjar, $\mathrm{PnD}^{1,2^{*}}$ and Joseph Burgett ${ }^{1}$ \\ ${ }^{1}$ Clemson University, Clemson SC, USA \\ ${ }^{2}$ dgajjar@clemson.edu
}

\begin{abstract}
The use of Unmanned Aircraft Systems (UAS) or Drones are being explored for a wide range of civilian applications. The Federal Highway Administration (FHWA) recently reported that "construction inspectors that use UAS are reducing inspection time, improving effectiveness, increasing safety, and lowering costs." If the FHWA is enjoying these benefits by leveraging this technology, it stands to reason that other industries that perform similar functions would also benefit. This study explores the opportunity of using commercially available UAS and structure-from-motion software to replace an in-person inspection for a low slope roof. The goal of the study was to see how much of a traditional in-person roof inspection could be replaced with a 3D photogrammetric model created from drone imagery. In this experiment, a SME roofing inspector identified deficiencies exclusively from a 3D model. Then, the SME inspected the low-slope roof in-person using traditional practices. The SME identified 191 specific deficiencies using 3D model and 200 deficiencies from the traditional method. The defects easiest to identify were open laps, alligatoring, punctures, wrinkles on the roof membrane and damages around the edges whereas total number and square feet of blisters, damages around penetration were the most difficult to identify in the model.
\end{abstract}

\section{Introduction}

Over the past several years, civilian use of Unmanned Aircraft Systems (UAS) or drones has increased dramatically and made significant inroads into many industries and markets. The FAA reports that over one million drones have been registered in the US and they expect this number to grow to over seven-million by 2020 (Essex, 2016). One of the reasons that has led to the significant increase in drone use is the deregulation of the airspace. Title 14 Part 107 of the Code of Federal Regulations was released in August of 2016 and significantly reduced the restrictions on using UAS for commercial activities (Federal Aviation Administration, 2018). One of the leading federal agencies taking advantage of drone technology is the Federal Highway Administration (FHWA). In a recent publication, the FHWA claims that "construction inspectors that use UAS are reducing inspection time, improving effectiveness, increasing safety, and lowering costs" (FHWA, 2019). This assertion has been 
well supported in the literature with several studies by state DOTs finding that UAS have the potential to save thousands of dollars per inspection (AASHT0, 2016). If state DOTs are able to enjoy such significant savings by leveraging this technology, it stands to reasons that other industries performing similar tasks can also benefit from it. This paper outlines an experiment where a commercially available drone and post-processing software were used to create a 3D model of an existing roof near the end of its useful life. A subject matter expert (SME) roofing inspector performed an inspection using only the 3D model and then inspected the roof in person using traditional methods. The results of the two inspections were then compared to evaluate the effectiveness of the technology.

\section{Literature Review}

Historically, UAS have primarily been used for military applications. The first recorded use of a UAS dates back to 1839 when the Austrians used explosive filled hot air balloons to attach the Venetians (Dronethusiast, 2019). Nikola Tesla's radio-controlled model boat paved the way to what is more traditionally thought of as drones in 1898. The British's "Queen Bee" was a modified de Havilland DH82D and used as a radio-controlled target aircraft for anti-aircraft target practice during World War 2 (de Havilland Aircraft Museum, 2019). The Queen Bee is generally thought to have been the inspiration for the term "drones" making the comparison to stingless male bees (Economist, 2017). The US military made significant strides using UAS for surveillance in the 1970s following the botched Cuban Bay of Pigs invasion and the removal of troops from the Vietnam War (Przybilla and WesterEbbinghaus, 1979).

Despite the history with the military, UAS are being leveraged for more and more civilian use cases. Some of the applications in the construction industry that have shown promise in the literature include construction safety monitoring (Gheisari, Irizarry and Walker, 2014), disaster management (Adams, Levitan and Friedland, 2014), land surveying (Aguera-Vega, Carvajal-Ramirez and MartinezCarricondo, 2017), stockpile calculations (Hugenholtz, Walker, Brown, and Myshak, 2014), landslide monitoring (Lucieer, de Jong, and Turner, 2014), bridge inspection (Dorafshan and Maguire, 2018) and construction progress monitoring (Lin, Han and Golparvar-Fard, 2015).

Specific to the roofing industry, UAS have seen its application mainly in thermal studies (Krawczyk et. al., 2015; Zhang et. al., 2015; Rakha et. al., 2018) and best practices on how to fly UAS for roof inspections (Bown and Miller, 2018). Moisture has a direct impact on the performance of roofing systems. A thermal study is conducted to detect the moisture underneath the roofing membrane on the deck during roof install and / or during roof inspections to prevent moisture from building up. Previous research concludes that UAS that have IR cameras attached can successfully capture thermal images to detect deck moisture. Another study by Brown and Miller (2018) examined a standardized process for inspecting sloped roofs with UAS and concluded that horizontal approach of flying across the roof is disadvantageous over vertical approach due to less skill required for a pilot to perform a roof inspection. In spite of UAS proving to be advantageous in the field of roofing industry, a study of the comparison of various inspection points for low-slope (defined as less than 1:12 by the IBC) roofing system and the effectiveness of the UAS technology versus a traditional in-person inspection remains to be explored. This study will contribute by further exploring the effectiveness of using UAS's in detecting existing roof conditions during inspections beyond moisture detection. Moreover, because of the speed at which new technology is being developed and new use cases identified, past studies remain relevant for only a short period of time (Hugenholtz et al., 2014). 


\section{Methodology}

The research methodology for this study is outlined in figure 1 below.

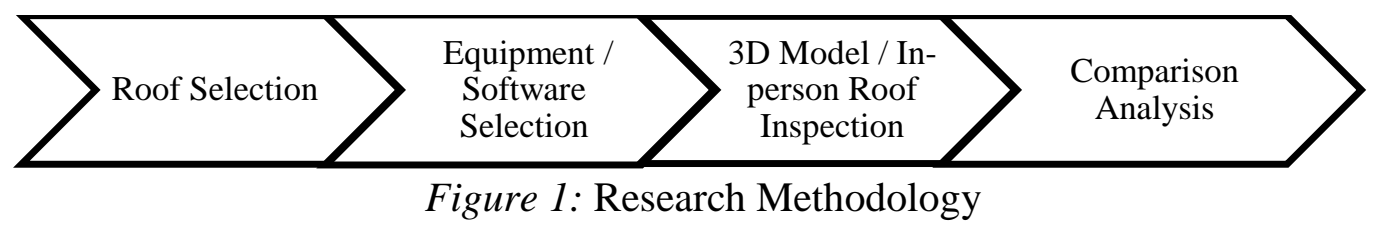

\subsection{Roof Selection}

It was important to identify a roof with sufficient defect data points for a comparison between the two inspection methods. Hence, ease of access to the roof, the age of the roof and the number of defect points on the roof were the key selection factors for this study. With this in mind, the researchers reached out to the facilities department at a public university to evaluate the various roofs installed on-campus. With the input of the roof maintenance manager and the SME roofing inspector, a low-slope roof that was installed in 1999 (20 years old) with multi-ply modified bitumen roof membrane was selected (figure 2).

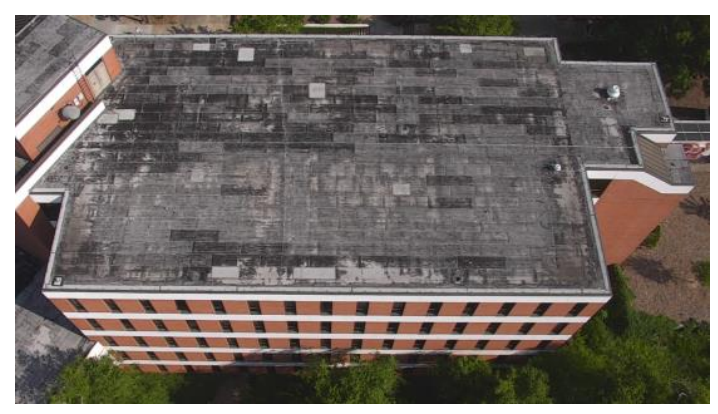

Figure 2: Subject Roof

\subsection{Photogrammetry}

The term "photogrammetry" is generally defined as the use of images to create a 3D model that can be measured. The process is automated using "structure-from-motion" (SfM) software. Images captured with most professional grade drones have the GPS position of the drone and the direction and angle of the camera recorded in the image file metadata. The SfM software orientates the images and extracts unique features in the images. The unique features are then identified in other images included with the dataset and stitched together in a process called "aerial triangulation." ContextCapture, Pix4D, PhotoScan and DroneDeploy are some of the more commonly used SfM applications. DroneDeploy is web based only where the others also have a desktop version for local data processing. Local processing can take anywhere from a few minutes to a few days or weeks depending on the number of images, 
image file size and computer processing power. Web based processing can be significantly faster but often have a fee per process or a monthly subscription cost for the service.

\subsection{Equipment and Software}

For this experiment, two Da-Jiang Innovations (DJI) drone were used. This first was a Phantom 4 Pro (P4P) and is equipped with a 1 " complementary metal-oxide semiconductor capturing, 20megapixels sensor. The camera is mounted below a 3-axis stabilized gimbal. This aircraft was used to collect images to create the base framework of the model.. A preprogrammed flight was created using the Pix 4D capture application where the drone flew approximately 50' above the roof surface with $80 \%$ overlap between pictures. The camera was angled at 10 degrees to capture elevation changes on the roof surface. The second UAS used was DJI's M210RTK model (figure 3). This is a general purpose aircraft that can support a variety of sensors. For this experiment, a Zenmuse Z30 camera was selected. The Z30 provides a 30x optical zoom allowing for detailed image capturing without flying near obstructions. This aircraft was used to capture images around penetrations, flashing and other areas where roof failures commonly occur. The high resolution images increased the resolution in the model at locations where building envelope failures are most common.

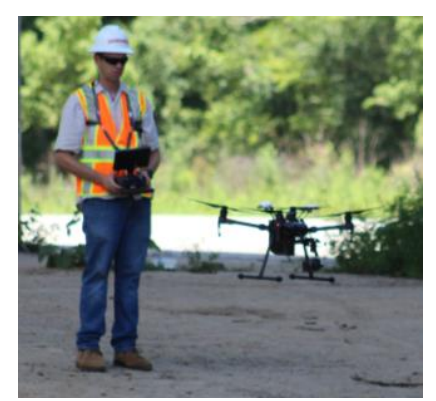

Figure 3: M210RTK and Pilot

The SfM software used in this experiment was Bentley's ContextCapture. ContextCapture is a high powered SfM package that produces a wide range of photogrammetric outputs such as TIN, DGN, 3MX and OBJ files. Generally, most photogrammetric models have a "waxy" appearance. This happens when the software cannot triangulate all the data in the images precisely. One of the important reasons why ContextCapture was selected is that within the software there is a mode where the user can select any point in the model and all images used to create that point are displayed. The waxy model can be used for an overall review of the roof, but more importantly, can be used as an image management tool. Instead of looking through potentially thousands of images to find a particular inspection point, the inspector can simply click on the model and potentially dozens of images taken at different positions can be reviewed. See figure 4 to illustrate. Additionally, Bentley offers the software free of cost for educational and research purposes making it very accessible for this experiment. 


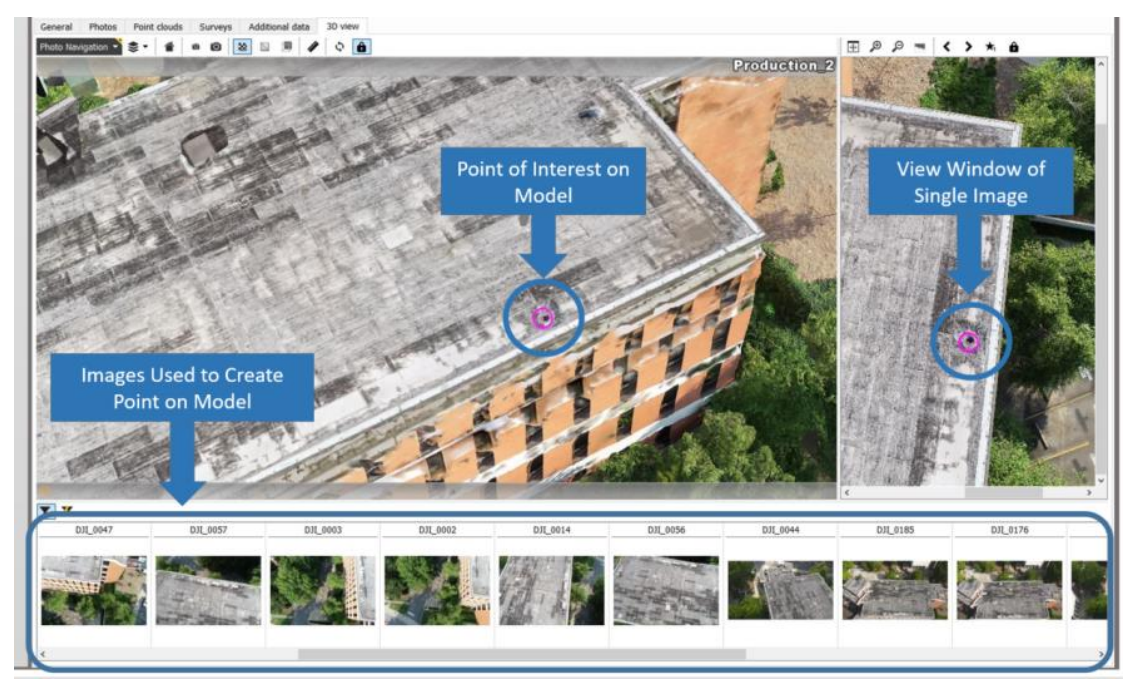

Figure 4: 3D Model Use to Inspect Roof

\subsection{D Model / In-person Roof Inspection}

After capturing the 3D model of the subject roof, the SME roofing inspector was trained on using the software and how to navigate through the model. Mainly with the use of images captured through 3D modeling, the SME roofing inspector conducted the roof assessment inspection remotely with the use of inspection checklist that recorded the various defects relevant to the roofing industry such as blisters, open laps, alligatoring, punctures, wrinkles, damages around penetrations and edges and blocked gutters and downspouts. In order to avoid human bias, the SME roofing inspector did not have access to walk the roof prior to the $3 \mathrm{D}$ model roof inspection.

Two days after 3D model roof inspection, the SME roof inspector conducted a traditional in-person roof assessment inspection on the same subject roof using the same inspection checklist used with the 3D model. The inspection data points were recorded immediately on the roof as the inspection was being conducted. Figure 5 provides several examples of the defects observed on the roof.

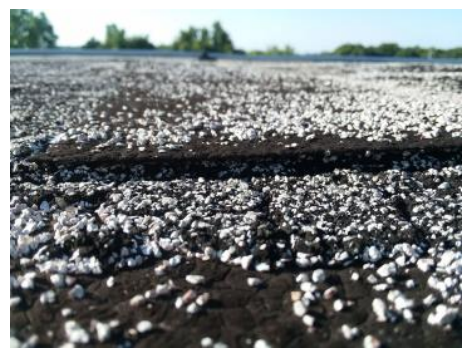

Open Lap

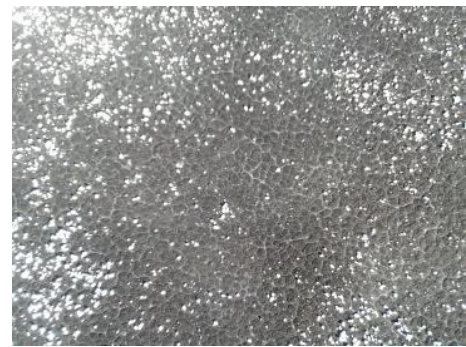

Alligatoring

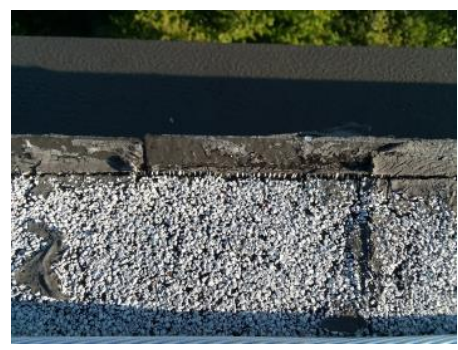

Damage at the Edge

Figure 5: Examples of Defects Observed on Roof 


\subsection{Comparison Analysis}

The inspection data points for the 3D model and in-person roof inspection were analyzed in relation to the objectives of the study as follows:

1. Compare the inspection time and general roof details (number of penetrations and type of ballast).

2. Compare various defects such as blisters, open laps, alligatoring, punctures, wrinkles, damages around penetration, edges and parapet walls and blocked gutters and downspouts. Also identify defects documented that are within 20\% margin error between 3D model inspection and in-person inspection.

\section{Results}

Table 1 outlines the comparison between inspection time and general roof details between 3D model inspection and in-person inspection.

Table 1

Inspection Time and Roof Details Comparison

\begin{tabular}{lcc}
\hline \multicolumn{1}{c}{ Criteria } & 3D Model Inspection & In-person Inspection \\
\hline Date Inspected & $8 / 5 / 19$ & $8 / 7 / 19$ \\
Inspection Start Time & $12: 20 \mathrm{PM}$ & $8: 35 \mathrm{AM}$ \\
Inspection End Time & $1: 38 \mathrm{PM}$ & $9: 20 \mathrm{AM}$ \\
Total Inspection Time & 78 mins. & 45 minutes \\
Drone Inspection Flight Time and Modeling & 25 mins. & $\mathrm{n} / \mathrm{a}$ \\
Roof Ballast - Granules / Aggregate / None & Granules & Granules \\
Total number of roof penetrations & 10 & 10 \\
\hline
\end{tabular}

The total inspection time for 3D model including drone flight time and in-person inspection was one hundred and three (103) mins and forty-five (45) mins respectively. The observation points for roof ballast and total number of roof penetrations were similar for both 3D model inspection and in-person inspection.

Table 2 outlines the comparison for various defects between 3D model inspection and in-person inspection. The Percent Difference column is the percentage of deviation between the $3 \mathrm{D}$ model Inspection and In-person Inspection, relative to the In-person Inspection.

Table 2

Defect Comparison

\begin{tabular}{lccc}
\hline Criteria & $\begin{array}{c}\text { 3D } \\
\text { Model } \\
\text { Inspection }\end{array}$ & $\begin{array}{c}\text { In- } \\
\text { person } \\
\text { Inspection }\end{array}$ & $\begin{array}{c}\text { Percent } \\
\text { Difference }\end{array}$ \\
\hline Total Blisters (SF) & 7 & 61 & $771 \%$ \\
\hline
\end{tabular}




\begin{tabular}{lccc}
\hline Total Blisters (\#) & 4 & 22 & $450 \%$ \\
Total Open Laps (\#) & 5 & 5 & $0 \%$ \\
Total Alligatoring (\#) & 99 & 107 & $8 \%$ \\
Total Punctures (\#) & 4 & 4 & $0 \%$ \\
$\quad$ Total Wrinkles (\#) & 17 & 15 & $13 \%$ \\
$\quad$ Total Damaged Flashing Penetrations & 23 & 15 & $53 \%$ \\
$(\#) \quad$ Total Damaged Flashing Parapet Wall & 35 & 31 & $13 \%$ \\
$(\#) \quad$ Blocked Gutters \& Downspouts (\#) & 0 & 3 & $100 \%$ \\
$\quad$ Blocked Drains (\#) & 4 & 0 & $100 \%$ \\
\hline
\end{tabular}

Various defects comparison between 3D model inspection and in-person inspection reveals that the total number of blisters and the total square feet of blisters have a significant margin error over $100 \%$. There were no blocked gutters and downspouts identified from the 3D model inspection, but three blocked gutters and downspouts were identified during in-person inspection. Similarly, there were no blocked drains identified during in-person inspection compared to 3D model inspection. Other defect factors such as total laps, alligatoring, punctures, wrinkles and damages around parapet walls were within $20 \%$ margin error. The 3D model inspection identified 191(\#) specific deficiencies compared to 200 using the traditional in-person method.

\section{Conclusion}

The objective of the study was to outline an experiment where a commercially available drone and post-processing software was used to create a 3D model of an existing roof near the end of its useful life. Comparing various defect rates between 3D model inspection and in-person inspection for a low-slope was also a key aspect of this study. Based on the findings, it was concluded that UAS has its advantages in performing roof assessment inspections for low-slope roofing. Some of the advantages of using UAS for inspecting roofing systems include the overall safety of the inspector since it could eliminate the need to physically walk the roof, any damages caused on the roof by the inspector during the inspection walk and a detailed log of images over a period of time captured during the UAS flying. It was also concluded that UAS are efficient (within $20 \%$ margin error) for capturing defects from top-view such as open laps, alligatoring, punctures, wrinkles and damage around edges or parapet wall.

One of the major disadvantages was that the 3D model inspection lasted 32 mins longer compared to an in-person inspection. This could be due to the SME roofing inspector not having any formal education on using the modeling software. In order to reduce the roof assessment inspection time, it is recommended that a formal education be provided to the roofing inspector on how to navigate the software. Defects that require section view such as total number of blisters, blocked drains, gutters and downspouts and damage around penetrations had significant margin errors (more than $20 \%$ margin error) between 3D model inspection and in-person inspection. This could be due to the lack of knowledge on the critical roofing elements to capture for the drone pilot or a need for higher quality drone camera that can zoom in closer at the fine details. Some of the other limitations for not being able to inspect a roofing system with the use of UAS include the presence of conflicting structures such as trees, surrounding taller buildings and federal enforced no-flying zones. 
In spite of the limitations, UAS can prove to be an effective technology in conducting roofing inspections. Future research and investigation are needed on use of UAS for inspecting multiple lowslope roofing systems since this study only included one low-slope roofing system, developing a protocol and standard as to when an in-person inspection is required, and use of UAS to perform steep-slope roofing systems that have diverse building shapes and roof profile.

\section{References}

AASHTO. (2016). Survey Finds a Growing Number of State DOTS are Using Drones to Improve Safety and Collect Data Faster and Better-Saving Time and Money.

Adams, S., Levitan, M., \& Friedland, C. (2014). "High resolution imagery collection for postdisaster studies utilizing unmanned aircraft systems (UAS)." Photogrammetric Engineering \& Remote Sensing, 80(12), 1161-1168.

Aguera-Vega, F., Carvajal-Ramirez, F., and Martinez-Carricondo, P. (2017). "Accuracy of Digital Surface Models and Orthophotos Derived from Unmanned Aerial Vehicle Photogrammetry." Journal of Surveying Engineering, 143(2): 04016025

Bown, M., \& Miller, K. (2018). The Use of Unmanned Aerial Vehicles for Sloped Roof Inspections - Considerations and Constraints. Journal of Facility Management Education and Research, 2(1), 12-18. doi: 10.22361/jfmer/93832

Dorafshan, S. \& Maguire, M. J Civil Structural Health Monitoring (2018) 8: 443. https://doi.org/10.1007/s13349-018-0285-4

Dronethusiast. (2019). "The History of Drones (Drone History Timeline from 1849 to 2019)." (https://www.dronethusiast.com/history-of-drones/)

de Havilland Aircraft Museum. (2019). "de Havilland DH82B Queen Bee.” (https://www.dehavillandmuseum.co.uk/aircraft/de-havilland-dh82b-queen-bee/) retrieved August $29^{\text {th }}, 2019$.

Economist. (2017). “Technology Quarterly - Taking Flight” (June 6 ${ }^{\text {th }}$ ) (https://www.economist.com/technology-quarterly/2017-06-08/civilian-drones) retrieved August $29^{\text {th }}$, 2019.

Essex, A. (2016). Taking off: State Unmanned Aircraft Systems Policies. National Conference of State Legislatures.

Federal Aviation Administration. (2018). "Fact Sheet - Small Unmanned Aircraft Regulations (Part 107).” (https://www.faa.gov/news/fact_sheets/news_story.cfm?newsId=22615) retrieved May $17^{\text {th }} 2019$.

Federal Highway Administration (FHWA), (2019). "Innovation of the Month: Unmanned Aerial Systems. (August) https://www.fhwa.dot.gov/innovation/everydaycounts/edcnews/20190815.cfm

Gheisari, M., Irizarry, J., \& Walker, B.N. (2014). "UAS4SAFETY: The potential of unmanned aerial systems for construction safety applications." Proceedings of the Construction Research Congress 2014, 1801-1810.

Hugenholtz, C., Walker, J., Brown, O., \& Myshak, S. (2014). "Earthwork volumetrics with an unmanned aerial vehicle and softcopy photogrammetry." Journal of Surveying

Engineering, 10.1061.

Krawczyk, J., Mazur, A., Sasin, T., \& Stokłosa, A. (2015). Infrared building inspection with unmanned aerial vehicles. Transactions of the Institute of Aviation, 240(3), 32-48. doi: $10.5604 / 05096669.1194965$ 
Lin, J.J., Han, K.K., \& Golparvar-Fard, M. (2015). “A framework for model-driven acquisition and analytics of visual data using UAVs for automated construction progress monitoring." Computing in Civil Engineering, 156-164.

Lucieer, A., S.M. de Jong, and D. Turner. (2014). "Mapping landslide displacements using Structure from Motion (SfM) and image correlation of multi-temporal UAV photography." Progress in Physical Geography, Vol. 38, No. 1, 2014, pp. 97-116.

Przybilla, H.-J., Wester-Ebbinghaus, W. (1979). "Bildflug mit ferngelenktem Kleinflugzeug. Bildmessung und Luftbildwesen. Zeitschrift fuer Photogrammetrie und Fernerkundung." Herbert Wichman Verlag, Karlsruhe, Germany.

Rakha, T., \& Gorodetsky, A. (2018). Review of Unmanned Aerial System (UAS) applications in the built environment: Towards automated building inspection procedures using drones. Automation in Construction, 93, 252-264. doi: 10.1016/j.autcon.2018.05.002

Zhang, J., Jung, J., Sohn, G., \& Cohen, M. (2015). Thermal Infrared Inspection Of Roof Insulation Using Unmanned Aerial Vehicles. ISPRS - International Archives of the Photogrammetry, Remote Sensing and Spatial Information Sciences, XL-1/W4, 381-386. doi: 10.5194/isprsarchives-xl1-w4-381-2015 